
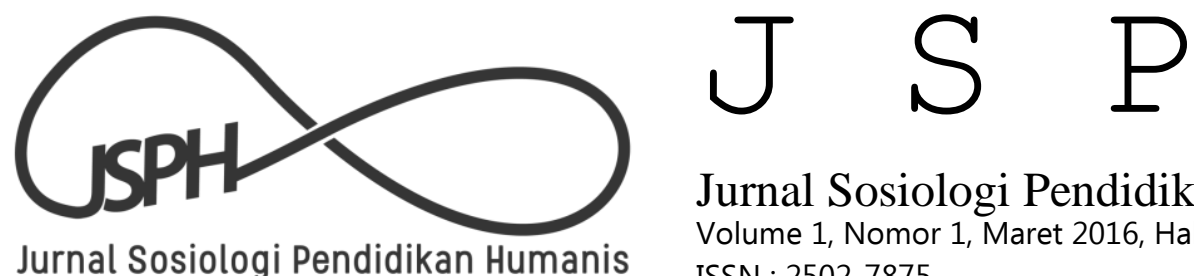

Jurnal Sosiologi Pendidikan Humanis

Volume 1, Nomor 1, Maret 2016, Halaman 21-27

ISSN : 2502-7875

\title{
PASUKAN KHUSUS PANGERAN DIPONEGORO MASIH MENARI (STUDI HISTORIS KESENIAN TARI TRADISIONAL REYOG BULKIYO BLITAR)
}

\author{
Irfan Santoso \\ Komunitas Reyog Bulkiyo Blitar \\ Email:arjuno_blitarian@yahoo.co.id
}

\begin{abstract}
Abstrak
Perang Sabil yang lebih dikenal dengan sebuatan Perang Jawa (De Javasche Oorlog dalam bahasa Belanda) mempunyai dampak dalam sejarah nasional maupun sejarah lokal. Perang itu merupakan fenomena sosial yang terjadi hampir di seluruh Pulau Jawa. Setelah Pangeran Diponegoro sebagai pemimpin perang tertangkap oleh Belanda pada 28 Maret 1830, banyak dari pasukan Pangeran Diponegoro yang melarikan diri ke berbagai pelosok daerah untuk menghindar dari operasi pembersihan sisa prajurit oleh Belanda. Akibat dari pelarian itu, mereka banyak yang menyamar menjadi rakyat biasa dan bertahan hidup hingga akhirnya mempunyai hasil karya seperti misalnya kesenian. Reyog Bulkiyo merupakan kesenian tari hasil dari olah pikir prajurit yang melarikan diri dari kejaran Belanda. Kesenian tari ini terdapat di Desa Kemloko Kecamatan Nglegok Kabupaten Blitar yang dahulu pada tahun 1825 disebut sebagai daerah bumi Mancanegara Wetan masuk kedalam pembagian wilayah Kasunanan Surakarta. Reyog Bulkiyo memiliki ciri khas yang menunjukan bahwa ada tiga unsur budaya terangkai dalam satu pertunjukan ritme gerak tari yaitu budaya Jawa, Islam (Arab) dan, Cina. Eksistensi kesenian ini hingga kini masih bisa dinikmati dalam festival budaya, pentas seni maupun acara-acara pemerintahan. Namun, di era modernisasi seperti ini, kesenian tradisional seperti Reyog Bulkiyo harus di jaga dan dilestarikan guna menambah dan mempertahankan ciri khas ke Indonesiaan Bangsa ini.
\end{abstract}

Kata Kunci: reyog bulkiyo, identitas, eksistensi

\section{DIPONEGORO SPECIAL FORCES STILL DANCING (STUDY OF HISTORICAL TRADITIONAL DANCE ARTS OF REYOG BULKIYO BLITAR)}

\begin{abstract}
Holy War is better known as the Java War (De Javasche Oorlog in Dutch) have any impact in national history and local history. War is a social phenomenon that occurs in almost all of Java. After Diponegoro as a war leader was caught by the Netherlands on March 28, 1830, many of the troops of Diponegoro who fled to various parts of the area to stay away from the rest of the precleaning operation by the Netherlands. As a result of the escape, they many are disguised as ordinary people and survive until the end to have the work such as art. Reyog Bulkiyo a result of the dance art process to think soldiers fleeing from the Netherlands. Dance Arts is located in the Kemloko District of Nglegok Blitar, which is called in 1825 Bumi Mancanegara Wetan the part of Kasunanan Surakarta. Reyog Bulkiyo has a characteristic that shows that there are three cultural elements strung in the rhythm of dance performances that Javanese culture, Islam (Arabic) and China. This art can still be enjoyed in cultural festivals, art performances and events administration. However, in the era of modernization such as this, traditional arts such as Reyog Bulkiyo must be guarded and preserved in order to increase and maintain the typical characteristics of Indonesia to this Nation.
\end{abstract}

Keywords: reyog bulkiyo, identity, existence 


\section{LATAR BELAKANG}

Kebudayaan adalah seluruh sistem gagasan dan rasa, tindakan, serta karya yang di hasilkan manusia dalam kehidupan ber masyarakat, yang dijadikan miliknya dalam bentuk belajar (Koentjaraningrat, 1996 :72). Pola dari belajar itu, dimulai dari gagasan berlanjut ke rasa setelah itu tindakan, dan yang terakhir adalah karya. Secara tidak langsung hampir seluruh tindakan manusia itu adalah budaya, sedangkan tindakan yang dilakukan tanpa belajar itu adalah sebuah naluri. Cara manusia makan itu adalah kebudayaan sedang tindakan makan itu adalah sebuah naluri ketika manusia merasa lapar. Jadi kebudayaan itu, tindakan yang dilakukan manusia dengan belajar dan berpola sehingga menjadi kebiasaan.

Indonesia memiliki beranekaragam kesenian, mengingat Indonesia adalah negara dengan masyarakat yang multikultural, keanekaragaman ini ialah bentuk kekayaan dan keunikan yang mempunyai nilai tinggi. Kesemuanya itu merupakan suatu harta karun yang harus dijaga dan dilestarikan. Maka penting adanya pelestarian terhadap keanekaragaman. Dalam hal pelestarian tidak hanya para seniman atau pemerintah, akan tetapi kita semua yang berwarga negara Indonesia, sebagai bentuk rasa nasionalisme.

Blitar, nama tempat yang terkenal karena di daerah tersebut tempat penyimpanan abu Raden Wijaya (Raja Kerajaan Majapahit) di Candi Simping dan disemayamkanya presiden pertama Republik Indonesia Ir. Soekarno. Eksistensi Blitar dimata nasional tidak diragukan, selain itu kekayaan akan budaya Indonesia juga terdapat di daerah ini, seperti Grebeg Pancasila, Seruling Penataran, Gong Perdamaian, Kesenian Kentrung, Wayang
Kulit dan masih banyak lagi kesenian tradisional yang masih bisa dinikmati di daerah ini.

Jika kita berbicara tentang kesenian tradisional Jawa Timur, mungkin yang terlintas dipemikiran kita adalah kesenian tradisional yang memang sudah terkenal di dunia internasional misalnya kesenian tari Reyog Ponorogo, orang akan berfikir bahwasanya ketika terdengar kata reyog besar ke mungkinan merujuk pada suatu kota yaitu Ponorogo, padahal di lain tempat masih banyak reyog-reyog lain, dengan berbagai bentuk penyajian dan ciri khas masing-masing.

Banyak ditemui kesenian yang juga menggunakan kata reyog dengan berbagai macam bentuk sajian. Ada dua sosok penting dalam reyog yakni Warok dan Gemblak. Selain itu reyog juga terkait erat dengan Jaran Kepang. Jenis tari Jaran Kepang di daerah Yogyakarta dan sekitarnya lazim disebut dengan Jathilan (Muntadhirotul, 2014:2). Reyog dengan bentuk penyajian yang berbeda, seperti misalnya sebuah penelitian skipsi penulis yaitu kesenian tari tradisional Reyog Bulkiyo. Kesenian ini merupakan seni tari tradisional yang terdapat di Desa Kemloko Kecamatan Nglegok Kabupaten Blitar.

Bulkiyo adalah salah satu corps pasukan pangeran Diponegoro yang mengadopsi dari pasukan elit Turki Ustmani "Boluc" mendapat pengaruh pelafalan Jawa menjadi Bulkiyo (Leirissa, 2009:233). Besar kemungkinan nama kesenian tari tradisional Reyog Bulkiyo terinspirasi dari pasukan pangeran Diponegoro. Selain itu Supangi yang menjadi generasi penerus juga mengatakan bahwa nama Bulkiyo diambil dari Serat Ambiya (cerita nabi) yaitu RajaBulkiyo yang berperang melawan raja mesir Karungkala.Seperti kesenian lainya 
karena sifat budaya yang dinamis Reyog Bulkiyo juga mengalami naik dan turun dalam eksistensinya, mulai dari terciptanya seni tari ini hingga sampai saat ini sudah ada tiga genarasi dan masih bisa dinikmati di daerah asal kesenian ini hidup dan berkembang.

\section{METODE PENELITIAN}

Dalam artikel ini penulis menggunakan metode historis dengan pendekatan kualitatif untuk merekam, mengkaji dan menganalisa tentang suatu kejadian (Sjamsuddin, 2007) dalam hal ini tentang Reyog Bulkiyo. Pengumpulan sumber (heuristik) dilakukan dengan mengumpulkan dokumen dan pustaka yang berkaitan dengan Reyog Bulkiyo. Tahapan-tahapan dalam penulisan penelitian sejarah ini ini juga dilakukan khususnya pada tahap verifikasi sumber dan interpretasinya.

\section{HASIL DAN PEMBAHASAN Sejarah Singkat}

De Javasche Oorlog merupakan peristiwa perang di tanah Jawa yang berlangsung antara tahun 1825-1830 yang lebih dikenal dengan Perang Diponegoro atau Perang Jawa. Menurut Ma'arif (2014:93-94) Perang Jawa adalah perang antara Pangeran Dipone-goro bersama rakyat Jawa melawan Belanda karena kesewenangannya terhadap Kesulta-nan Yogyakarta. Menurut Carey (2011:704) penyebab utama Perang Diponegoro adalah ketika pemerintah kolonial memutuskan untuk memperbaiki jalan-jalan kecil di sekitar Yogya, satu di antaranya melewati pagar sebelah timur Tegalrejo.

Struktur organisasi perang Pangeran Diponegoro berbentuk corps, yang meniru organisasi tentara kerajaan Turki Ustmani pada abad ke 16-18. Pasukan elit kerajaan Turki Utsmani terdiri atas tiga divisi yaitu
Boluck, Cemaat, dan Segmen. Pasukan infantrinya disebut Bashiboluck, nama-nama Turki tersebut diadopsi oleh Pangeran Diponegoro dengan lafal Jawa. Boluck menjadi Bulkiyo, Bashiboluck menjadi Borjomuah, Turki menjadi Turkiyo demikian pula pangkat komandan dan prajurit. Pangkat untuk pemimpin tertinggi adalah Ali Basah, hanya beberapa orang saja yang berpangkat Ali Basah, antara Ali Basah Sentot Prawiridirjo, Ali Basah Kerto Pengalasan dan Ali Basah Mohamad Ngusman (Leirissa, 2009:233).

Pada tanggal 25 Maret 1830 Jendral De Kock dengan secara rahasia memberi instruksi untuk menangkap Pangeran Diponegoro apabila perundingan gagal. Penundaan selama kira-kira 2 hari dalam bulan Ramadhan, memberi kesempatan pada Belanda untuk kemudian merencanakan penangkapanya. Perundingan yang diadakan pada tanggal 28 Maret 1830 ternyata berakhir dengan kegagalan dan Pangeran Diponegoro ditangkap (Leirissa, 1990:204).

Tertangkapnya Pangeran Diponegoro mengakibatkan perlawanan selama 1825-1830 tidak membuahkan hasil, banyak pengikut Pangeran Diponegoro yang menyerahkan diri terhadap Belanda seperti Kiyai Mojo dan Sentot Prawirodirjo dan sisa sisa prajurit banyak yang melarikan diri di berbagai daerah pelosok agar tidak tertang-kap oleh pasukan Belanda, karena setelah Pangeran Diponegoro ditangkap, Belanda akan mencari dan menangkap sisa-sisa prajurit $\mathrm{Pa}$ ngeran Diponegoro yang dimungkinkan melakukan pemberontakan lagi.

Blitar ialah salah satu tempat pelarian sisa-sisa Pangeran Diponegoro, sebab daerah Blitar secara geografis merupakan tempat di mana keadaan tanah sangat subur, mengingat bahwa masih berada dekat deng- 
an gunung Kelud yang masih aktif. Selain keadaan tanah suburyang bisa dijadikan sisa-sisa prajurit Pangeran Diponegoro untuk bertahan hidup dengan cara membuka lahan untuk bertani, tempat ini masih banyak hutan dan pemerintah Belanda belum menaruh perhatian khusus pada Blitar sebelum terbentuknya Gementese-hingga aman untuk persembunyian atau penyamaran sisa-sisa prajurit oleh pencarian pasukan Belanda.

Bermula dari peristiwa inilah suatu kesenian tari tradisional Reyog Bulkiyo diDesa Kemloko Kecamatan Ngglegok Kabu-paten Blitar tercipta oleh Kasan Muhtar dan masih lestari hingga saat ini. Kasan Muhtar merupakan salah satu prajurit Pangeran Diponegoro berasal dari Bagelan Jawa Te-ngah yang melarikan diri di daerah pelosok Blitar. Nama Reyog Bulkiyo kemungki-nan besar diambil dari salah satu corps parajurit Pangeran Diponegoro yaitu corps Bulkiyo, mengingat bahwa yang menciptakan kesenian tersebut merupakan salah satu sisa-sisa parajurit yang melarikan diri serta gerak tarianya layaknya gerakan olah kanuragan prajurit yang berperang menggunakan pedang.

\section{Identitas Reyog Bulkiyo}

Keunikan atau ciri khas Reyog Bulkiyo Blitar terdapat pada awal mula terciptanya kesenian tersebut, seperti yang penulis ungkapkan dalam sub bab sebelumnya. Dari peralatan musik yang mengiringi mengandung tiga unsur budaya yaitu Jawa, Arab, dan Cina. Kembali pada Reyog Bulkiyo, seuatu karya seni sebagai representasi Perang Jawa sangat wajar bahwasanya kesenian itu mengandung tiga unsur budaya. Budaya Jawa, mengingat peristiwa perang terjadi hampir diseluruh Jawa, budaya Islam Arab, karena sang pemimpin Perang Jawa, Pangeran Diponegoro yang merupa-kan penganud madzab Islam Sufisme serta adanya motivasi Perang Jawa adalah mendirikan negara Islam (Balad). Warna budaya Cina juga memperlihatkan akulturasi pada Reyog Bulkiyo, sebab ketika peristiwa Perang Jawa orang Tionghoa (Cina) yang menjadi sasaran operasi perang, meskipun dalam perkembanganya, menurut Djamhari (2014:105) pasukan Pangeran Diponegoro juga membeli senjata dari Orang Cina.

Dari segi perlengkapan dan peralatan juga terdapat akulturasi dari tiga budaya.

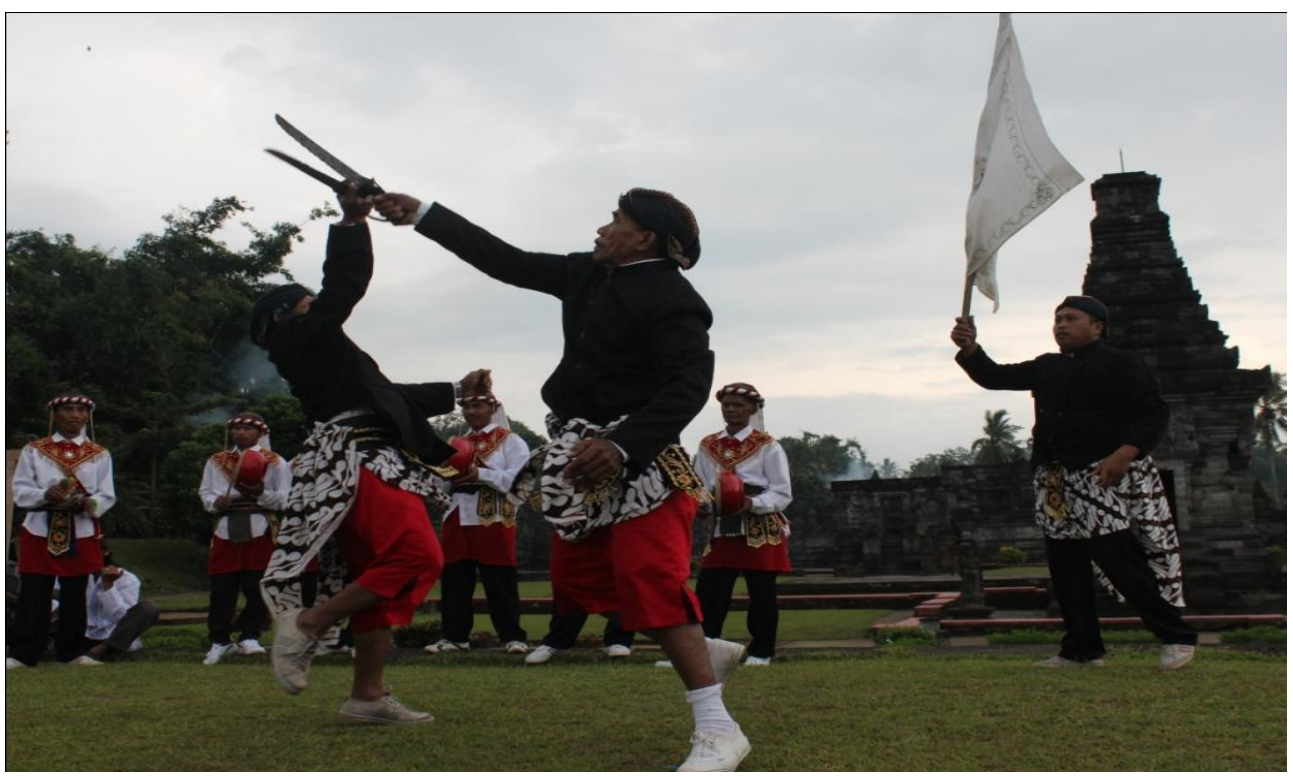

Gambar 1 Gerakan Perang Reyog Bulkiyo (Dokumentasi Pribadi) 
Pertama, budaya Jawa diantaranya Blangkon dengan gaya Yogyakarta, kain batik bermotif parang rusak, baju Beskap dan Atela. Blangkon yang dipakai para penari ada dua macam yaitu, Blangkon dengan mondholan dan Blangkon dengan gayasintingan keduanya khas gaya Yogyakarta. Ada yang dari Blangkon yang dipakai penari pembawa alat musik terbang (Penari Prajurit), sebuah perpaduan blangkon dengan liltan kain merah dan putih disebut Udeng Gilik Bawang Sebungkul. Atribut ini hampir mirip dengan pakaian perang pasukan Janisari Turki Ustmani abad 16. Keris, dipakai oleh setiap penari Reyog Bulkiyo Blitar. Keris yang dipakai bergaya Yogyakarta dengan warngka branggah. Cara yang digunakan untuk memakai keris juga bergaya mogleng Yogyakarta.

Dengan demikian, jika kita tarik benang merah, antara sejarah singkat, ciri khas, dan motif atau gaya busana Reyog Bulkiyo, adalah seni tari identitas para pelaku seninya. Identitas untuk para pejuang ketika Perang Jawa terjadi, disisi lain, dimungkinkan juga sebuah seni identitas ini untuk memberitahukan kepada sanak saudara yang nasibnya sama-sama sebagai pelarian masa Perang Jawa berakhir tahun 1830.

\section{Eksistensi Reyog Bulkiyo}

Bagaikan menyusuri jalan pegunungan berkelok dan naik turun dengan samping kanan kiri, bola mata memandang jurang bertebing-tebing itulah mungkin gambaran bagi eksistensi Reyog Bulkiyo.Eksistensi adalah suatu proses yang dinamis, suatu "menjadi" atau "mengada" ini sesuai dengan asal katanya existere, yang artinya "keluar dari" atau "mengatasi" dirinya sendiri. Jadi eksistensi tidak bersifat kaku dan terhenti, melainkan lentur dan mengalami perkembangan atau sebaliknya kemunduran (Abidin, 2002:10).

Ada dua faktor yang mempengaruhi eksistensi dan masih bertahan hidupnya kesenian tari tradisional Reyog Bulkiyo Desa Kemloko Kecamatan Nglegok Kabupaten Blitar. Pertama, faktor intern dan kedua, faktor ekstern. Faktor Intern, berasal dari kesenian tari Reyog tersebut sedangkan faktor ekstern, berasal dari luar kesenian,yaitu masyarakat yang menikmati pertunjukanya. Faktor intern berasal dari kegigihan para pelaku seni yang mempertunjukan kesenian Reyog Bulkiyo dan mewariskanya kepada generasi berikutnya. Pola pewarisannya pun masih bersifat turun-temurun mulai dari terbentuknya tahun 1932 hingga sampai saat ini.Faktor ekstern, ini merupakan hal yang sangat penting seagai pendukung dan secara tidak langsung juga sebagai pelestari sebuah kesenian. Faktor ekstern tergolong kedalam penikmat dan pengkaji kesenian Reyog Bulkiyo. Penikmat bisa digolongkan pada penonton dan pemerintah setempat, sedang dari pengkaji dapat digolongkan pada peneliti dan instansi yang berhubungan

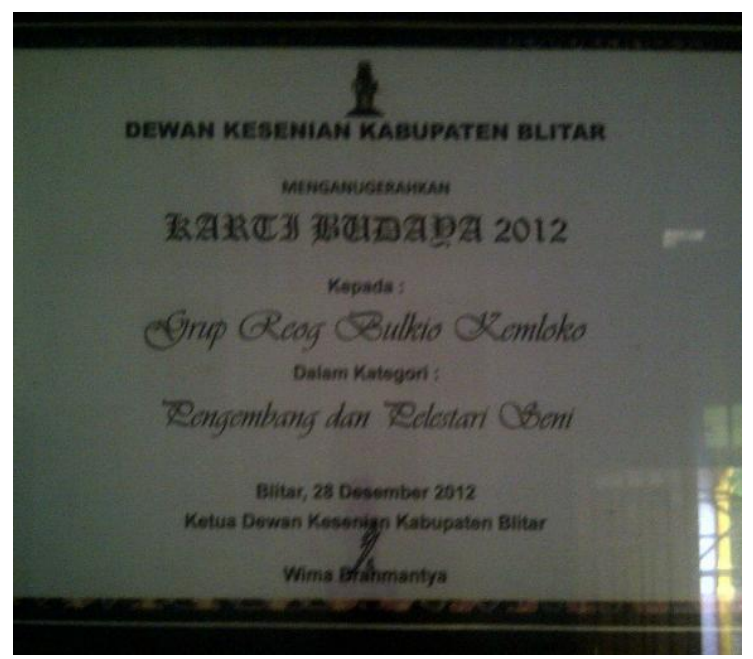

Gambar 2 Piagam Penghargaan "Karya Budaya 2012” (Sumber: Santoso.I, 2015:183) 
dengan kesenian.

Pada tahun 1980 masa-masa kejayaan Reyog Bulkiyo kesenian tersebut dipertunjukan rutinan setiap acara suran atau bulan suro (hitungan bulan dalam budaya Jawa) dan maulid nabi Mohammad S.A.W. Selain itu, dari pemerintah Kota Blitar, Reyog Bulkiyo sering diundang dalam acara-acara festival seni. Pada tahun 2011 Reyog Bulkiyo diundang untuk menari dalam acara Festival Penataran 2011 "Pertunjukan Seni dan Pasar Rakyat". Pada tahun 2012 kesenian Reyog Bulkiyo Blitar juga mendapat penghargaan dari Dewan Kesenian Kabupaten Blitar (DKKB) sebagai pengembang dan pelestari budaya.

Eksistensi Reyog makin bersinar ketika media komunikasi juga ikut berpartisipasi dalam mengenalkan Reyog Bulkiyo dalam tingkat nasional. Pada 31 Januari 2014 media televisi swasta telah meliput Reyog Bulkiyo dan menayangkan dalam program acaranya untuk membantu mengenalkan kekayaan dan kebudayaan Indonesia pada tingkat nasional maupun Internasional. Tidak hanya media, mahasiswa pun sudah banyak yang mulai membahas tentang Reyog Bulkiyo. Paling tidak ada tiga peneliti yang mengkaji kesenian Reyog Bulkiyo dari berbagai sudut pandang seperti, Listiana, Novia D. mahasiswa seni tari Universitas Negeri Malang pada tahun 2012 dalam skripsinya meneliti dari sudut pandang makna dibalik ragam gerak Reyog Bulkiyo, Saraswati mahasiswa satu jurusan dengan Listiana, dalam sebuah skripsinya pada tahun 2013 meneliti Reyog Bulkiyo sebagai pengenalan pendidikan muatan lokal di tingkat sekolah, dan pada tahun 2014 Ana Muntadhirotul, mahasiswa Institut Seni Indonesia (Surakarta) dalam karya sikripsinya meneliti dari sudut pandang koreografi Reyog Bulkiyo.

\section{KESIMPULAN}

Penulis berharap, dengan adanya karya ilmiah ini bisa membantu pelestarian kesenian tari tradisional Reyog Bulkiyo. Penulisan ini diharapkan mampu memberikan bantuan kepada pemerintah Kabupaten Blitar sebagai sumber tertulis mengenai kesenian Reyog Bulkiyo. Untuk penelitian selanjutnya, penulis berharap ada penelitian tentang Kesenian Reyog Bulkiyo yang memfokuskan pada ranah pendidikan, mengenalkan ataupun mengajarkan kesenian Reyog Bulkiyo pada anak tingkat Sekolah Dasar, agar nantinya kesenian Reyog Bulkiyo mempunyai generasi penerus sampai kapanpun, serta ikut membatu menjaga ciri khas dan identitas budaya Indonesia di tengah arus modernisasi.

\section{DAFTAR PUSTAKA}

Abidin, Zaenal. (2002). Analisis Eksistensi Untuk Psikologi Dan Psikiatri. Bandung: PT. Refika Aditama.

Carey, Peter B.R. (2011). Kuasa Ramalan (Jilid II). Pangeran Diponegoro dan Akhir tatanan lama di Jawa 1785 1855. Jakarta: Kepustakaan Populer Gramedia.

Djamhari, Saleh As'ad. (2014). Strategi Menjinakan Diponegoro (Stelsel Bneteng 1827 - 1830). Jakarta: Komunitas Bambu.

Harwimuko, (2012). Ensiklopedia Seni Budaya Kabupaten Blitar. Blitar: Primatama.

Koentjaraningrat. (1996). Pengantar Antropologi I. Jakarta: PT. Rineka Cipta.

Leirissa, R.Z. (1990). Sejarah Nasional Indonesia (jilid IV). Jakarta: Balai Pustaka. 
Leirissa, R.Z. (2009). Sejarah Nasional Indonesia IV (edisi Pemutakhiran). Jakarta: Balai Pustaka.

Ma'arif, Syamsul. (2014). Jejak Kesaktian Dan Spiritual Pangeran Diponegoro. Yogyakarta: Araska.

Muntadhirotul, Ana. (2014). Tijauan Koreografi Reyog Bulkiyo Di Desa Kemeloko Kecamatan Nglegok Kabupaten Blitar. Skripsi tidak diterbitkan. Surakarta: Institur Seni Indonesia Surakarta.

Santoso, I. (2015). Eksistensi Kesenian Reyog Bulkiyo Kabupaten Blitar
(Studi Pelestarian Kesenian Tari Tradisional Reyog Bulkiyo Desa Kemloko Kecamatan Nglegok Kabupaten Blitar). Skripsi tidak diterbitkan. Malang: Prodi Pendidikan Sejarah Fakultas Ilmu Sosial Universitas Negeri Malang.

Sjamsuddin, Heulis. (2007). Metodologi Sejarah. Yogyakarta. Ombak

Suparlan, P. (1984). Manusia, Kebudayaan dan Lingkungannya. Jakarta: C.U. Rajawali. 